\title{
A NOTE ON THE DEEP TRANSVERSE FIBRES OF THE PONS.
}

\author{
BY E. E. LASLETT, M.B., B.SC.
}

Late Demonstrator of Physiology, Univ. Coll, Liverpool; Assist. Med.

Officer, Park Hospital, London.

THE lesion on which the following observations are founded was discovered while examining the nervous system of a patient who died from cerebral hæmorrhage. The patient was" under the care of Dr. James Barr, at the Royal Infirmary Liverpool, and I am much indebted to him for permission to publish this note.

Although lesions of the pons are not very rare, yet an opportunity of examining the resulting degenerations is comparatively uncommon, and the injury in this instance is an unusually favourable one for the study of the course and relations of the deep transverse fibres.

The pons was hardened in Müller's fluid for a month, and thin slices treated with Marchi's fluid in the usual way. Sections were cut after paraffin embedding.

Lesion.-This is situated in the lower part of the upper half of the pons, about $2 \mathrm{~mm}$. from the median raphe, and so placed as to intercept several large bundles of cross-fibres immediately posterior to the pyramidal tract, and, indeed, to involve to a small extent two bundles of the latter tract. In cross-section it is of an irregularly oval shape, with its long diameter, about $3 \mathrm{~mm}$. in length, transverse. It extends about $2 \mathrm{~mm}$. from above downwards.

It is apparently a softened patch, due most probably to thrombosis of some of the small vessels. There are no signs of hæmorrbage in it, old or recent. Microscopical examination of the softened area shows that it consists of a compact mass of leucocytes, traversed by one or two 
capillaries; these, as well as the small surrounding vessels, being full of blood. The leucocytes are large, and accompanied by numerous giant-cells, both varieties being filled with granules blackened by the osmic acid.

The lesion is strictly unilateral and does not approach the middle line nearer than $2 \mathrm{~mm}$. at any point, and is, I think, unusually interesting on account of its circumscribed character.

Transverse fibres.-These are degenerated on both sides

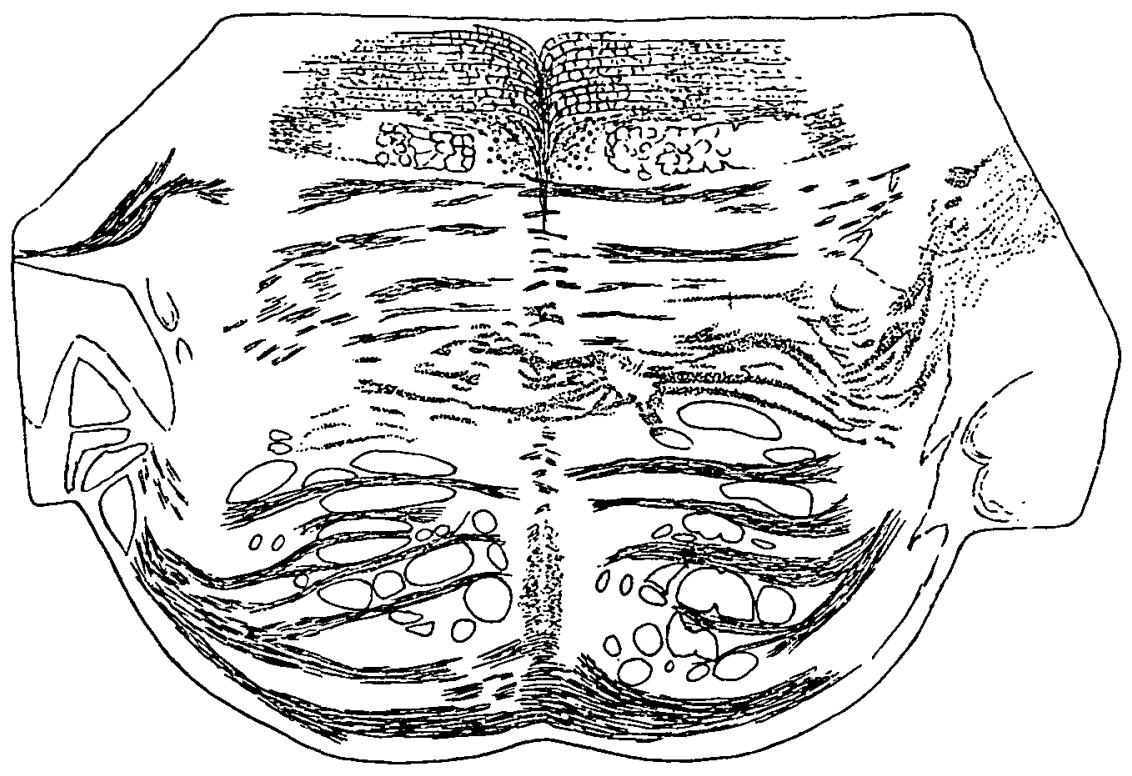

F'IG. 2.

of the pons, but the altered fibres are much more numerous on the side of the lesion than in the opposite half.

A section at the level where the softened area is greatest shows the following features (fig. 2):-(1) On the outer side of the lesion there is beavy degeneration in three main bundles of the cross-fibres, in several minor bundles in the immediate neighbourhood, and also in a thin transverse tract considerably posterior to the main part. Following these tracts laterally, they are seen to break up into smaller 
bundles, extending over a large area, in the region of the lateral gray matter, and here apparently many of them end. Large numbers of fibres, however, pass beyond the gray matter, and enter in a more or less scattered fashion into the middle cerebellar peduncle, occupying mainly its inner: half.

There is also a small degeneration in two of the posterior bundles of the pyramidal tract.

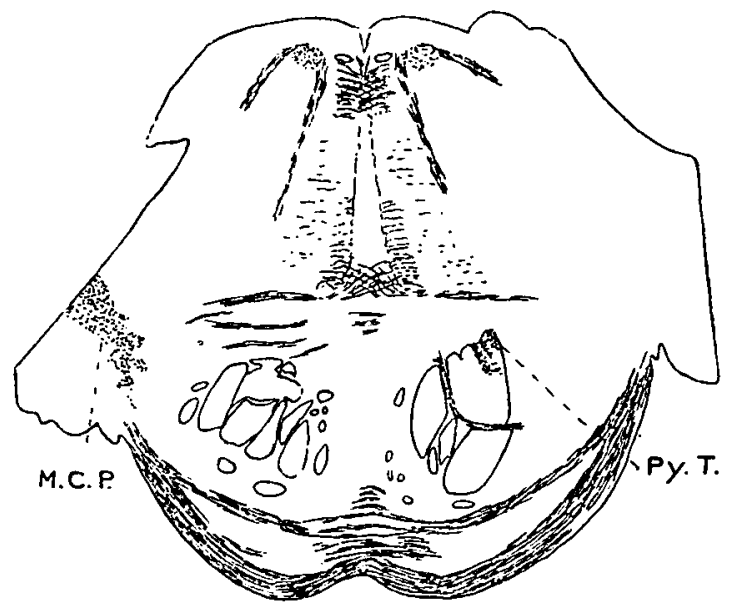

FIG: 1.

Section through the lower limit of pons.

M.C.P.-Degenerated tract in the middle cerebellar peduncle.

Py.T.-Degenerated fibres of the pyramidal tract.

Section at the level of the lesion. The main features are drawn carefully to a magnification of four diameters, so that the area over which the degeneration spreads is accurately represented.

(2) On the inner side of the lesion there is degeneration, also in three bundles. These pass directly to the median raphe, where they cross and have the same course as the above. A few scattered small bundles are seen in the neighbourhood of the raphe some little distance posterior to the lesion. The section from which the figure in the plate was drawn is slightly oblique, and consequently the mode of termination of these fibres on this side is not 
shown, but in all respects it is the same as on the side of the lesion.

Sections somewhat above or below this level show the same general appearances, but the number of degenerate fibres diminishes, of course, with the area of softening.

Fig. 1 represents a section through the pons at its lower limit, below the injury. The only descending degeneration is in the posterior part of the pyramidal tract. This is small, and due to the fact above-mentioned, that the softening encroached slightly upon two small bundles of the aforesaid tract. The further course of this degeneration I had not the opportunity to follow. On the opposite side there are still seen some of the cross-fibres remaining, most of which are passing into the middle cerebellar peduncle. The degeneration remaining in the other middle peduncle at this level is too scattered to be represented in the figure.

Sections above the lesion show no degeneration in the fillet or the posterior longitudinal bundle, nor are there any fibres ascending to the corpora quadrigemina.

By studying sections immediately above and below the lesion it is seen that the degenerated transverse fibres are practically confined to the level of the injury, this being an indication that they maintain a fairly horizontal course until they reach the lateral limit of the pons, where, of course, they dip backwards somewhat with the middle cerebellar peduncle.

The lesion from its nature and situation cannot throw much light on the origin of these fibres, but some interesting points as to their destination may be ascertained. Pellizi (1) finds that destruction of the middle lobe of the cerebellum causes degeneration in the median field of the middle peduncle and in the stratum profundum of the pons. According to Cajal ponto-cerebellar fibres spring from the cells of the pontine nuclei. These cross the middle line and pass to the cerebellum by way of the middle peduncle of the opposite side. This is in all probability the origin of many of the degenerated fibres in the present case.

The exact constitution of the middle cerebellar peduncle 
is not by any means a settled question. Marchi, and Ferrier and Turner found, after destruction of one half of the cerebellum, complete atrophy of the middle peduncle and of all the cross fibres of the pons. Risien Russell states that the latter fibres pass to the pons ganglia of the opposite side.

On the other hand, according to Thomas (2), the above lesion entails degeneration of only a small portion of this peduncle, and he concludes that its fibres are passing from the pons to the cerebellum. Klimow (3) similarly comes to the conclusion that this peduncle consists largely, if not exclusively, of centripetal fibres, originating in a great measure from the.pons gray matter of the opposite side with a termination in the flocculus and hemisphere.

The degenerated fibres in the middle peduncle in the present case are, of course, centripetal, and although they are scattered in each section, yet from the depth through which they extend one must conclude that there is a very considerable number of them.

Inasmuch as the lesion is so near the middle line, one may conclude that all the damaged fibres of the same side have really crossed. Nevertheless, one is unable definitely to decide upon the origin of tuese fibres, wbich is in all probability a multiple one. Their termination, however, is definitely twofold, namely, (1) in the pons ganglia; (2) in the cerebellum.

\section{REFERENCES.}

(1) Revista Sperim, vol. xxi. Ref., Neurolog. Centralbl., 1895.

(2) Lue Cervelet.

(3) Die Leitungsbahnen d. kleinen Gehirns. Ref., Bechterew die Leitungsbahnen. 